\title{
TWO CASES OF PECULIAR MOVEMENTS IN CHILDREN.
}

BY W. HALE WHITE, M.D.,

\author{
Senior Assistant Physician to Guy's Hospital.
}

CaSe I.-A. A., æet. 14, came to my Out-patients' department on March 2nd, 1886. The notes made at the time are as follows:-

$\mathrm{He}$ is healthy-looking and very intelligent, being at the top standard but one at the Board School. He is an only child; a paternal uncle is in an asylum, otherwise the family history is very good. Forceps were used at birth, from which time his mother has noticed irregular twitchings of his muscles. When he was three months old, she took him to the Great Ormond Street Hospital. The doctor said he would grow ont of it, and gave him cod-liver oil; but he has not improved.

Present Condition.-On watching the boy, occasional slow involuntary movements of the fingers and forearms are seen more on the right side than the left, where indeed they are hardly perceptible. These movements affect the face and both extremities on the slightest attempt at voluntary movement, and indeed they may at times be seen on the face without any voluntary motion. They are least marked in the lower extremity. When at their greatest they are extreme, the platysma and trapezius showing the irregular spasmodic contractions very well. It cannot be made out that the muscles supplied by the 3rd or 5th nerves are affected. Perhaps the action which shows the trouble to the greatest perfection is unbuttoning his shirt: he makes the most irregular and violent attempts with his right hand; the right side of the face is distorted; the left hand tries to help, but is affected in the same way but to a less degree, and finally his mother has to help him ; but if he employ only the left hand he can after some time manage it. His handwriting is hardly legible, and he has to hold the right hand, which holds the pen, steady with the left. Owing to the face-affection the speech is irregular and jerky. The abdominal and thoracic muscles are not affected, but the affection of the right leg causes an irregular gait. All his troubles are worse when his attention is directed to them. The knee-jerks are normal, as is the triceps on the left side; but the attempt to get it on the right sets up the irregular movements. There is ankleclunus on both sides, and diminished superficial reflexes all over the body. No paralysis or contraction, no atrophy, no paradoxical contraction. Electrical reactions all normal. No disturbances of 
sensation. Ophthalmoscopic and laryngeal examination showed normal results. Special senses normal ; no trophic changes. No asymmetry of head, limbs, \&c.; no wasting; throat normal; uvule bifid; dentition is said to have been delaved. There is a narrow patch on the right leg.

March 1887.-For the past year he bas been treated with iodide of potaksium and tonics, but withuut any benefit. A most thorough examination showed the condition to be unchanged, except that no ankle-clonus could be obtained, and the reflexes were not so lively. He has not suffered from headache or sickness. As he has got used to me he does not make quite such extreme movements as he did at first when talking to me, but he is just as bad as ever with strangers. This patient was exhibited at a Clinical Meeting of the Neurological Society last March.

CAse II.-C. L., æt. 10, admitted under me into Philip Ward, Feb. 26th, 1887, for spasmodic movements of the right arm and right facial paralysis.

Family History.-The maternal great-grandfather had fits; he died, æt. 60, paralysed. A maternal great-aunt had fits; a first cousin (mother's sister's child) has fits and is weak mentally. The patient is the eldest of four. The second, a boy, was born with a large head and is very excitable. The third, a boy, has of'ten been operated on for nævi. The fourth, a girl, is healthy. The mother is healthy, but her mother from childhood has had tremblings of the head and right arm: she has had thirteen or fuurteen children, and is now almost bedridden.

Personal History.-His birth was a "hard confinement;" he was a nervous child, easily frightened, screaming when the clock struck. In May, 1886, he woke up one morning feeling sick and feverish. He was kept in bed a week, as he had a sore throat; his mother noticed he was a little shaky, loth hands being tremulous. He quite recovered. In July, 1886 , his mother again noticed tremulousness, confined to the right hand, though he could still feed himself; but by October it had got so bad that he could not write. At this time he described a pain which began in the right midfinger and extended up the arm. He was now remuved from school, where he had been looked upon as a dull boy, although he was in the second standard. His speech was noticed to be affected. By Nuvember the right arm was useless. He was taken to a doctor, who drew attention to slight facial paralysis and draguing of the right leg, and said he had either chorea or paralysis. He was taken to a hospital, where the eame diaguosis was made. Change of air was frequently tried, but he got no better, and was adnitted into Guy's. No rheumatism.

Condition on Admission.- Well-nourished, healthy-looking, dark hair and eyes; sits up in bed, amusing himself with toys and using the left hand exclusively. Has a small næroid patch on the left outer malleolus. There is nothing noteworthy about the mental condition. As far as the facial paralysis permits, tie pantomimic speech is good, as is the spoken, except for slow drawling but 
distinct utterance; this also would appear to be due to his paralysis. There is no aphasia. He cannot write. The only defects of the eyes are that the left pupil reacts better than the right; also, on looking up, the right eye is turned further up than the left; and in moving up, it performs slight horizontal oscillations. Hearing, taste, and smell normal.

Motor Functions. - There is paralysis of the muscles supplied by the right facial nerve, but it is very variable, the mouth being drawn violently to the left at one time, but not a few minutes after; both orbiculares palpebrarum and occipito-frontales muscles act equally and well. 'There is some paralysis of the left levator palpebre. The tongue is protruded normally. The uvula and palatine arches are equal. 'I'be power in both arms is diminished, but especially in the right. There is no paresis of the legs. When he sits naturally, the following is the position of the right upper extremity. The humerus is at the side, the forearm at a right angle over the chest, the hand is clenched, the thunb being adducted and pressed into the palm by the fingers. A.t irregular intervals spasmodic twitchings come on, mostly affecting the elbow joint, the closed hand being thus rubbed up and down the sternum and making an excursion of abont two inches. About a dozen of these twitches occur in as many seconds, and then the arm is still again for some minutes. If he is being watched, the movements are continuous; and if he is told to take one's hand, the whole extremity is irregularly thrown about before the object is accomplished. All this time the hand continues flexed, and he has to open it with the right before he can grasp anything. Occasionally the hand will open spontaneously. Although there is generally much rigidity at the elbow and hand, still if they are opened with some force they soon become flaccid, and also they may at times be opened with less trouble than at uthers; but the flaccidity soon gives way to contraction again, and the hand shuts up. The left arm is normal, except that at first there appeared to be some slight choreiform novements of it; but after he had been in a day or two, they disappeared. No wasting, anæesthesia, or reflexes of arm. In the right lower extremity the knee-jerk is absent, as is ankle-clonus and paradoxical contraction. As he lies in bed the foot is persistently extended at the ankle, the sole is arched, the toes are extended at the metatarso-phalangeal joint and flexed at the phalangeal; plantar reflex very sluggish. On walking, this rigidity of the foot passes off, but the patient has some inco-ordination, the right leg being swung too far round, and he very quickly throws the weight on to the left. Right lower normal. No electrical examination permitted.

Cases like these in some particulars have been recorded by Ross $^{1}$ and by Hadden. ${ }^{2}$ Must of the cases by Ross had more spastic rigidity than either of mine; the last is perhaps

' 'Brain,' Vol. V. p. 344.

2 'Clin. Soc. Trans.; vol. x viii. p. 221. 
doubtfully congenital, although it may be looked upon as a congenital disease supervening late in childhood; the first certainly is congenital. It is evident, on reading the accounts of them, that there is great difficulty in assigning to any one lesion the production of the symptoms in either case.

Until we know whether a lesion is present, and if so, what its position is, we have hardly enough basis for speculation as to causation of the symptoms. I intend to keep an eye on these two patients, and, if I outlive them, to complete the account of them. The cases that have beeri published of congenital brain deficiency in children producing symptoms, differ so among therselves, that they hardly form any guide in other cases. It is only by the recording of all these vague cases in which a diagnosis cannot be made that we can hope to eventually classify them, when we have had the opportunity of comparing a large number. 